\title{
ASSESSMENT OF CHILDREN'S ORAL HEALTH-RELATED QUALITY OF LIFE FOLLOWING FULL MOUTH REHABILITATION UNDER GENERAL ANAESTHESIA IN A GROUP OF EGYPTIAN CHILDREN
}

\author{
Ahmed Elkhadem* and Passant Nagi*
}

\begin{abstract}
Objectives: This study was performed on children and their families. The main aim was to discover the effect of dental treatment under general anaesthesia (GA) on quality of life in both children and their guardians.

Patients and Methods: The sample included a consecutive number of children receiving full mouth rehabilitation under GA. An interview was performed to the guardian's pre and postoperative. The interview consisted of a series of questions that examined the effect of dental caries on both the child and their guardians. Two scales were used in the process; the Early Childhood Oral Health Impact Scale (ECOHIS) to measure the impact of dental caries on children quality of life, and visual analogue scale (VAS) to measure guardian's satisfaction following GA.
\end{abstract}

Results: This study included 100 children and their guardians. The mean age for the whole sample was 4.5 years. The ratio of males to female children was 56:44. Regarding the results from ECOHIS, there was a statistically significant post-operative decrease in: complains from teeth, sensitivity with hot and cold, sensitivity from sweets, difficulty in pronouncing some words, time off from school or day-care due to pain, sleeping problems and behaviour problems. As for guardians, there was a statistically significant postoperative decrease in the feeling of being guilty towards their children welfare, the extra-care required for the child, the income loss and the worry about the child's future. Most of the parents (87\%) regarded the GA experience as being positive, and $85 \%$ of caregivers would recommend GA as a treatment option for full mouth rehabilitation in children.

Conclusions: The choice of GA as a treatment option for children with early childhood caries results in significant improvement in quality of life for both the children and their guardians.

\footnotetext{
* Lecturer, Pediatric Dentistry Department, Faculty of Oral \& Dental Medicine, Cairo University, Egypt.
} 


\section{INTRODUCTION}

Treatment of children with dental caries is usually a challenging procedure because the Pediatric dentist is required to possess operative skills as well as psychological management ones ${ }^{[1]}$. When the clinician is faced with uncooperative children, physical or mental disabled children, or ones with early childhood caries demanding more than multiple procedures, then one session treatment under GA seems to be an agreeable option ${ }^{[2]}$. The advantages of GA is to provide dental treatment in one setting with minimal psychological stress on the child. Further, the parental and child cooperation wouldn't be required, thus giving the clinician better environment for carrying out the dental treatment with less mental stress. ${ }^{[3]}$.

The quality and survival of different restorative treatment like crowns and composite restoration performed under GA have been examined in a previously published systematic review ${ }^{[4]}$. Meanwhile, the effect of dental treatment of children under general anaesthesia on the quality of life of both children and their parents in underinvestigated ${ }^{[5]}$. Children, in general, may not be able to convey their feeling of pain possibly because if their mental immaturity. Nevertheless, this pain can be manifested in through eating problems where the child avoids food substances that require prolonged chewing and thrives more to fluid substances. Further, pain can lead to an inability to sleep and an increase in the use of analgesics ${ }^{[6-9]}$.

To assess the impact of dental disease and treatment on the quality of life in both the children and their guardians, the Early Childhood Oral Health Impact Scale (ECOHIS) has been proposed ${ }^{[10]}$. A validated Arabic version has been published in $2017^{[11]}$ to be used in countries whose first language is Arabic. ECOHIS constitute questions that target the physical and psychological condition of the child prior to dental treatment and introduce the same questions following treatment. The guardian's quality of life in terms of time and income loss due to disease burden can be assessed using the same scale.

Therefore, this study aimed to investigate the quality of life for children and their parents before and after dental treatment under GA. The null hypothesis is that there will be no difference in the quality of child's life before and after full mouth rehabilitation under general anaesthesia. Thus, revealing changes in a child's life and behaviour together with parental satisfaction and effect on their income and time following treatment.

\section{PATIENTS AND METHODS:}

Patients were carefully assessed for eligibility by the investigators. The target population was healthy children without medical conditions to eliminate the impact of such conditions on the postoperative OHRQL. Children with age range 2 to 8 years suffering from caries in 4 or more teeth were eligible to participate. The guardians of the children should approve to take part in this study. The study was performed in a private dental centre located in Maadi, Cairo - Egypt, equipped with a GA facility unit.

The primary outcomes to be tested were the improvement in the child's dental symptoms together with enhancement in sleeping and social aspects. Besides, parental questionnaire examining the financial burden of dental decay was used. We used the Arabic version of "The Early Childhood Oral Health Impact Scale (ECOHIS)" [11] primarily developed in the English language by Pahel et al. at $2007^{[10]}$. We used that written questionnaire and face to face interview to assess parent's and child's satisfaction.

Verbal and written consent was obtained from the parents at checkup visit before the GA appointment, then the guardians complete the pre-treatment questionnaire and interview. Approximately one week following the child's full mouth rehabilitation, 
a post-treatment checkup is performed on the child, and guardian perform post-treatment interview and questionnaire. In case parents are not able to show up after one week, the questionnaire was performed through the phone. To motivate parents to come to the checkup visit, we offered free fluoride varnish application session two weeks after the GA session as a part of completing the rehabilitation.

A pediatric dentist ( $\mathrm{PN}$ ) performed the interview with the guardian. The interview and questionnaire were divided into two main themes; the first was related to the child's improvement in terms of pain reduction and ability to eat and sleep with minimal or no problems. The second theme was related to parental welfare in terms to decrease cost and time required for attention to the dental caries problem. Further, parents were asked to fill a visual analogue scale to test their satisfaction following the GA.

Baseline data included age at the time of treatment and gender. Statistical analysis was performed using SPSS computer program version 25 (IBM corporation). Pretest and posttest comparisons were performed using McNemar test with statistical cut off of $0.05^{[9]}$.

\section{RESULTS:}

Data were collected over a period of nine months. A hundred parents/caregivers of children receiving GA for dental treatment completed written questionnaires. The final sample included 56 boys (56\%) and 44 girls (44\%). The mean age of the whole sample was $4.5 \pm 1.2$ years. Before carrying on the full mouth rehabilitation under GA, the mean dmft was 9.1 \pm 4.1 . Different procedures were performed under GA and their distribution is provided in Table 1.
TABLE (1) The range of treatments provided under GA.

\begin{tabular}{|c|c|c|c|}
\hline Treatment provided & Number & $\begin{array}{c}\text { Mean per } \\
\text { operation } \\
( \pm \mathrm{SD})\end{array}$ & $\begin{array}{c}\text { Range } \\
\text { throughout } \\
\text { operation }\end{array}$ \\
\hline Composite anterior: & 46 & $0.9 \pm 0.6$ & $0-4$ \\
\hline Pulpectomy anterior & 160 & $3.8 \pm 0.8$ & $0-4$ \\
\hline Pulpotomy & 390 & $3.7 \pm 1.8$ & $2-8$ \\
\hline Esthetic crown & 203 & $2 \pm 0.6$ & $0-4$ \\
\hline anterior & 390 & $3.7 \pm 1.8$ & $2-8$ \\
\hline $\begin{array}{c}\text { Stainless steel } \\
\text { crown posterior }\end{array}$ & 52 & $0.5 \pm 0.2$ & $0-3$ \\
\hline Extraction & 90 & $0.91 \pm 0.3$ & $0-8$ \\
\hline Fissure sealant & & & \\
\hline
\end{tabular}

The impact of dental caries on the child pre and post full mouth rehabilitation under GA is presented in (Table 2). There was a statistically significant improvement with regards to complaints about teeth/gums and jaw, pronunciation of some words, following the operation and ability to finish the meals. The was a statistically significant reduction in snacking between meals, sleeping problems and taking time off school due to dental pain. Finally, there was an absolute reduction in pain with stimulus like hot, cold and sweets.

The impact of full mouth rehabilitation under GA on families was presented in (Table 3). Most parents or caregivers $(87 \%)$ regarded the GA experience as being positive, with the other $13 \%$ being neutral. There was a statistically significant reduction in the parent's sense of guilt towards their children. Besides, there was absolute reduction in the time lost income and time taken off work to attend for the consequences of dental caries. 
TABLE (2) The impact of dental caries on the child pre and post full mouth rehabilitation under GA

\begin{tabular}{|l|l|l|l|}
\hline Number of children who reported experiencing the effect 'all the time' or 'often' $(\%)$ & Post-treatment & P-value \\
\hline Questionnaire item & Pre-treatment & $4(4 \%)$ & $<0 \cdot 001$ \\
\hline 1-Complains about gums/tooth/jaw & $25(25 \%)$ & $0(0 \%)$ & - \\
\hline 2-Has pain or sensitivity with hot or cold & $30(30 \%)$ & $0(0 \%)$ & - \\
\hline 3-Has pain or sensitivity with sweet food & $50(50 \%)$ & $3(3 \%)$ & $<0 \cdot 001$ \\
\hline Is unable to finish meals & $37(37 \%)$ & $24(24 \%)$ & $<0 \cdot 001$ \\
\hline Snaking between meals & $74(74 \%)$ & $12(12 \%)$ & $<0 \cdot 05$ \\
\hline 4-Difficulty in pronouncing some words & $20(20 \%)$ & $1(1 \%)$ & $<0 \cdot 001$ \\
\hline 5-Taking time off day care or school due to dental pain & $39(39 \%)$ & $2(2 \%)$ & $<0 \cdot 001$ \\
\hline 6-Has sleeping problems & $12(12 \%)$ & $0(0 \%)$ & - \\
\hline 7-Has behaviour problems & $9(9 \%)$ & $6(6 \%)$ & $<0 \cdot 001$ \\
\hline 8,9-Avoid smiling, laughing or speaking among his mates & $60(60 \%)$ & & \\
\hline
\end{tabular}

TABLE (3) Impact on families pre- and post-treatment.

\begin{tabular}{|l|l|l|l|}
\hline \multicolumn{2}{|l|}{ Number of parents who reported impact ‘all the time' or ‘often' $(\%)$} & Post-treatment & P-value \\
\hline Questionnaire item & Pre-treatment & $4(4 \%)$ & $<0 \cdot 001$ \\
\hline $10,11-F e l t$ guilty/upset & $62(62 \%)$ & $0(0 \%)$ & - \\
\hline 12-Taken time off work & $63(63 \%)$ & $4(4 \%)$ & $<0 \cdot 001$ \\
\hline Child required extra care/attention & $30(30 \%)$ & $0(0 \%)$ & - \\
\hline 13-Lost income & $70(70 \%)$ & $7(7 \%)$ & $<0 \cdot 001$ \\
\hline Worried about child's future teeth & $86(86 \%)$ & & \\
\hline
\end{tabular}

\section{Assessment of the full mouth rehabilitation under $G A$}

Most parents/guardians were satisfied with the care provided under GA, and 87\% rated the experience as being positive (Table 4). Some parents (15\%) showed that they would not select GA option again, and most of them because of financial issues.

TABLE (4) Parental satisfaction with full mouth rehabilitation under general anaesthesia

\begin{tabular}{|l|l|}
\hline Questionnaire item & Number of yes respondents $(\%)$ \\
\hline Did you receive enough information before the operation? & $91(91 \%)$ \\
\hline Did you know where and how to ask for help following treatment? & $100(100 \%)$ \\
\hline Would you regard this experience as being positive? & $87(87 \%)$ \\
\hline Do you have any concerns regarding the treatment provided? & $3(3 \%)$ \\
\hline Is follow-up care arranged? & $99(99 \%)$ \\
\hline Would you consider general anaesthesia for treatment again? & $85(85 \%)$ \\
\hline
\end{tabular}




\section{DISCUSSION}

This study was performed to study the effect of full mouth rehabilitation under GA on the child's oral health quality of life and the impact of this treatment on the child's family.

\section{Quality of life for both the children and their families}

The mean dmft in children presented in this appear higher than a previous study ${ }^{[9]}$.About $30-50 \%$ of the parents reported that their children often had pain/sensitivity with hot/cold or had pain/sensitivity with sweets and this may explain why $37 \%$ of those children were unable to finish meals because they felt uncomfortable during eating. Up to $65 \%$ noted 'occasional' pain or problems. In consequence of that, the number of children snaking between meals increased to $74 \%$ to compensate for the inability to finish meals. However, all the children showed significant reduction in pain following treatment under GA.

Twenty per cent of the parents reported that their children had difficulty in pronouncing some words; this may be due to destructed anterior teeth due to caries. Not all cases which had pronunciation problem pre-treatment were improved two weeks posttreatment. Regarding sleeping problems, only 2 out of 12 children who had sleeping issues pre-treatment were still having a sleeping problem. However, they also had a breathing problem during sleep, so they were referred to ENT specialist for consultation on the possibility of having a sleep apnoea ${ }^{[12]}$.

Dental problems didn't show a dramatic effect on children behaviour in the current study since only 9\% of the guardians reported that their children had behavioural issues. The major complain from the parents that their children avoid smiling, laughing or speaking among his mates because they were shy to show their teeth, and this was shown more in the preschool and school-aged children between 5-7 years of age.

The reduction of dental pain experienced by the child was reflected by advances in eating, sleeping and child psychology. Another advantage following treatment was the reduction in the number of snacks possibly because children were able to finish their main meals without being interrupted with pain during chewing. Besides, the increased parental awareness of the danger behind frequent snacking might have lead to improvement in child's attitude. Long term follow-up study would be proposed to assess the longevity of parental awareness regarding the prohibition of frequent snaking.

There was an improvement regarding the impact of treatment under GA on the child's family. The mothers suffered from dental pain that presumably awakens the child at night. Also, some mothers reported that they would have to prepare food that doesn't require chewing so that the child would be able to finish the meal. In addition, the parents had to cut off their working hours to accompany their children to the dentist with resultant loss of income. These results confirm the burden of dental caries not only to the child but to the parents as well.

\section{Parental satisfaction with the care provided un- der general anaesthesia:}

Most parents (85\%) suggested that they would consider carrying out another GA for their child's dental treatment, rather than performing it while the child is awake. The rest (15\%) responded negatively to this question partly due to financial reasons and partly due to the psychological fear of parents from going to GA. This finding corresponds to other studies ${ }^{[9,13,14]}$.

In the current research, some of the children had caries removal or pulp therapy attempted in other 
dental clinics. Podesta and Watt reported that $70 \%$ of the children in their study had not been offered any alternative treatment options ${ }^{[14]}$. However, young children who have multiple carious lesions may not be able to tolerate several dental appointments, leaving full mouth rehabilitation under GA as the last resort. Eighty-seven per cent of the parents/ guardian thought positive of the GA experience

Nearly all the parents reported that they received enough information before treatment and knew where and how to access help after treatment. Also, parental were instructed to help their children with brushing teeth and the utilisation of fluoride varnish service every six months. This was stressed of during the first appointment pre GA appointment since previous studies reported that many of the parents who received advice regarding preventive care during the initial examination appointment before the GA but only $40-60 \%$ of the parents applied that advice ${ }^{[7,9]}$, and because of this, it was difficult to determine the long-term prognosis for these children's oral health.

The study was limited to a short period. Thus, we are planning to follow up those children for at least one year to monitor their prognosis in the long term. In addition, the results can' be generalised on low socio-economic families.

\section{CONCLUSIONS}

Treating children with a high disease experience, for Egyptian children came from moderate to high socioeconomic status families, in a single session under GA results in an immediate improvement in oral health and aspects of QoL for both the children and their families. Providing comprehensive dental treatment for young children under GA appears to be an acceptable approach for most parents in this study.

\section{Regarding the outcome of the current study:}

1. Children's quality of life after dental treatment under GA improved in terms of social, psychological and physical aspects.

2. Parents appreciate full mouth rehabilitation under GA.

3. Upcoming studies need to assess the long-term effects of dental treatment under GA on the patients' quality of life.

\section{REFERENCES}

1. Ramazani, N., Different Aspects of General Anesthesia in Pediatric Dentistry: A Review. Iran J Pediatr, 2016. 26(2): p. e2613.

2. El-Meligy, O., et al., The Effect of Full-Mouth Rehabilitation on Oral Health-Related Quality of Life for Children with Special Health Care Needs. J Clin Pediatr Dent, 2016. 40(1): p. 53-61.

3. Jankauskiene, B., J.I. Virtanen, and J. Narbutaite, Followup of children's oral health-related quality of life after dental general anaesthesia treatment. Acta Odontol Scand, 2017. 75(4): p. 255-261.

4. Jankauskiene, B. and J. Narbutaite, Changes in oral healthrelated quality of life among children following dental treatment under general anaesthesia. A systematic review. Stomatologija, 2010. 12(2): p. 60-4.

5. Lee, P.Y., et al., Comprehensive dental treatment under general anesthesia in healthy and disabled children. Chang Gung Med J, 2009. 32(6): p. 636-42.

6. Park, J.S., et al., Oral health-related quality of life changes in children following dental treatment under general anaesthesia: a meta-analysis. Clin Oral Investig, 2018. 22(8): p. 2809-2818.

7. Knapp, R., et al., Change in children's oral health-related quality of life following dental treatment under general anaesthesia for the management of dental caries: a systematic review. Int J Paediatr Dent, 2017. 27(4): p. 302-312.

8. de Souza, M.C., M. Harrison, and Z. Marshman, Oral health-related quality of life following dental treatment under general anaesthesia for early childhood caries - a UK-based study. Int J Paediatr Dent, 2017. 27(1): p. 30-36. 
9. Anderson, H.K., B.K. Drummond, and W.M. Thomson, Changes in aspects of children's oral-health-related quality of life following dental treatment under general anaesthesia. Int J Paediatr Dent, 2004. 14(5): p. 317-25.

10. Pahel, B.T., R.G. Rozier, and G.D. Slade, Parental perceptions of children's oral health: the Early Childhood Oral Health Impact Scale (ECOHIS). Health Qual Life Outcomes, 2007. 5: p. 6.

11. Farsi, N.J., et al., Validation of the Arabic Version of the Early Childhood Oral Health Impact Scale (ECOHIS). BMC Oral Health, 2017. 17(1): p. 60.
12. Tamasas, B., T. Nelson, and M. Chen, Oral Health and Oral Health-Related Quality of Life in Children With Obstructive Sleep Apnea. J Clin Sleep Med, 2019. 15(3): p. 445-452.

13. Holt, R.D., R.H. Chidiac, and D.C. Rule, Dental treatment for children under general anaesthesia in day care facilities at a London dental hospital. Br Dent J, 1991. 170(7): p. 262-6.

14. Podesta, J.R. and R.G. Watt, A quality assurance review of the patient referral process and user satisfaction of outpatient general anaesthesia services for dental treatment. Community Dent Health, 1996. 13(4): p. 228-31. 